\title{
Epilogue
}

\section{Bewilderment and Modern Fiction}

Modern fiction is a literature of bewilderment. James, Conrad, and Ford are among the first of a long series of novelists who value bewilderment for its ability to disclose the fundamental hermeneutic and semiotic processes that make up our worlds. Robbe-Grillet is only partly disingenuous when he justifies the bafflement his reader undergoes: "If the reader sometimes has difficulty getting his bearings in the modern novel, it is in the same way that he sometimes loses them in the very world where he lives." Everyday life is of course usually not as disorienting as Joseph K.'s bizarre trial by an endless series of unattainable, capricious judges, or as confusing as the ever-shif ting multiplicity of literary styles and modes of perception in Ulysses. But for that very reason we tend to take for granted the givenness and stability of the world around us. The ease with which we ordinarily find and keep our bearings is precisely what discourages us from critically examining the acts of interpretation we are constantly engaged in.

By blocking comprehension, modern fiction asks us to reconsider the functioning of signs and interpretation. ${ }^{2}$ The goal of such reconsideration

\footnotetext{
${ }^{1}$ Alain Robbe-Grillet, For a New Novel, trans. Richard Howard (New York: Grove Press, 1965), pp. 136-37.

${ }^{2}$ Modern fiction extends and redirects the revelatory function that incomprehension typically performs in narrative. Mikhail M. Bakhtin argues that "the moment of notunderstanding" is "an essential structural element of prose fiction" because, by not knowing the prevailing codes, values, and beliefs, the fool discloses what they are (see Bakhtin, Die Ästhetik des Wortes, ed. Rainer Grubel [Frankfurt: Suhrkamp, I979], p. 282). In nineteenth-century fiction the revelations that surprise and confusion bring are usually social and moral-as, for example, in Père Goriot where the muddlement of young Rastignac making his first afternoon calls provides Balzac with a vehicle for illuminating the spoken and unspoken laws of conduct in Parisian high society.
} 


\section{Epilogue}

may be pleasure, instruction, or both. Our liberation from the natural attitude ("reality is simply there") may release in us possibilities of meaningmaking which we had not known we had. Or we may achieve an increased self-consciousness about how we interpret and signify, including a new awareness of the limits and vulnerability of everyday semiotic processes. Or both may occur in various changing combinations.

The transitional role of James, Conrad, and Ford in moving the novel away from moral and social realism toward its modern focus on meaning and understanding can be seen in their contradictory combination of monism and pluralism. All three share a premodern faith in the empirical realm, although in each case this conviction wars with an opposing sense of the world's inherent variability. With James, for example, we encountered a contradiction between his belief in a single, determinate "reality" that ultimately "cannot not be known" and his fascination with the protean compositional powers of consciousness to construe and construct its world according to an endless variety of principles, purposes, and interests. This epistemological contradiction takes ontological form in Conrad, whose monistic longing to disclose the invisible essence of the "visible universe" stands in opposition to his anguished recognition that the world's irreducible multiplicity makes any approach to Being at most provisional and partial. In a similar effort to disclose the essential stuff of the real, Ford appeals to fiction to descend beneath the falsity of "narration" to the authentic realm of "Life." This deeper level is not univocal and stable, however, but variable, flickering, and obscure, with all the opalescence and ambiguity of unreflected "impressions." The literary impressionists' inherited commitment to novelistic realism is uneasily in tension with their increasing awareness of the multiplicity and instability of a universe of signs.

Modern fiction redefines the relation between monism and pluralism. The alternatives are typically no longer a single, determinate reality or the multiplicity of the phenomenal world. The question for many of the great twentieth-century novelists is how to respond to a universe where sign leads only to sign, without empirical reference. At the extremes, the alternatives available to them are either to acknowledge as inescapable the infinite multiplicity of possible modes of understanding which endless semiosis implies, or to seek transcendence by invoking a foundation for meaning and value beneath the contingencies of the hermeneutic field.

The attitudes of those who take the first route can range from celebration to skepticism and despair. One of the deepest paradoxes about Ulysses, for 
example, is that it defies the reader's efforts to understand it for the very reason that it makes so monumental a tribute to the human capacity to mean (the same is true on an even larger scale of Finnegans Wake). Ulysses could expand endlessly as Joyce varies his style of depiction and his angle of vision. The implication is that the "reality" it renders-even if so seemingly matter of fact as a normal day in the life of Leopold Bloomis infinitely multiple and changeable. The superfluity of possible connections and speculations Ulysses encourages us to project makes reading the novel a joy, a frustration, and a challenge. The novel both welcomes and undermines our attempts to discover hermeneutic constructs that would adequately organize its seemingly inexhaustible variety and complexity. The inability of any single construct-including the notorious Homeric parallels-to assimilate all the novel's parts into a consistent whole denies the assumption that meaning is simply "there" to be uncovered. ${ }^{3}$ By simultaneously stimulating and frustrating the reader's quest for understanding, Ulysses calls upon us to enlarge and interrogate our capacities to interpret and mean.

Kafka's readers experience similar challenges and frustrations, but their function is less to celebrate than to demystify. The baffled Joseph K. hopes that the chaplain's commentary will make sense of the ambiguous parable of the gatekeeper, but he finds himself increasingly thwarted as the string of opposing interpretations grows longer and longer. In much the same way, the reader of The Trial is tempted to believe that some secret key would unlock the hidden meaning and order of the seemingly inexplicable, fantastic events Kafka narrates-but again and again we find that the potential multivalence of any single part prevents it from resting quietly in any given whole. The proliferation of possible interpretations makes the meaning of the novel paradoxically more opaque than transparent. The paradox here is also Joseph K.'s dilemma: the more one interprets, the less one understands. The ceaseless deferral of meaning which leads interpretation from sign to sign is for Kafka distressing but inescapable proof of the final elusiveness of any redeeming truth. The multiplicity of modes of commentary is more obscuring than revealing because the variety of hermeneutic conflict testifies less to our powers to create meaning than to our inability to transcend the contingencies of a limited, partial vision.

Between celebration and skepticism, Thomas Mann deploys all the resources of irony to support an attitude of creative resignation toward

${ }^{3}$ Also see Wolfgang Iser's analysis of Ulysses in The Implied Reader (Baltimore, Md.: Johns Hopkins University Press, I974), pp. I96-233. 


\section{Epilogue}

hermeneutic multiplicity. In The Magic Mountain the bewildered Hans Castorp feels increasingly dizzy as the demonic Naphta and the liberal Settembrini seek to convert him to their ways of construing the world. In their endless quarrels, Castorp finds (as does the reader) that their positions seem to become less clear the more they explicate them. Their opposition refuses dialectical resolution, but neither Naphta's violent nihilism nor Settembrini's cheery humanism seems complete and adequate in itself. The uncomprehending Castorp lacks the intellectual ability or the moral courage to discover the only way out of this impasse which Mann's novel suggests - an ironic attitude that holds together, in the tension of perpetual mutual criticism, opposites that cannot be reconciled or transcended. Castorp's failings are a challenge to the reader to rise above them. Although Mann is often considered a holdover of nineteenth-century realism, the hermeneutic implications of his irony suggest a modern awareness that a single "truth" may not be available to stop the exchange of signs. In lieu of the conclusive interpretation Castorp seeks to settle the dispute between his teachers, Mann's irony is a way of accommodating relentlessly incompatible hermeneutic opposites.

For those moderns who refuse to accept a universe of conflicting "truths" as the final state of things, the way of monism is still open. But if they seek to transcend the uncertainty and variability of signs, they must also come to grips with the dilemma that the essence they desire can only be achieved by passing through the differentiated realm of interpretation. This is the modern version of the problem of mediation which idealism must always overcome. From Plato through Hegel this problem is typically stated in terms of the relation between ideas and knowledge, but there is also of course a long tradition of hermeneutic reflection about signs and transcendence. By asking what if anything lies beyond hermeneutic conflict, modern fiction introduces this tradition into the history of the novel.

Virginia Woolf and D. H. Lawrence figure among the most interesting modern monists because they meet the challenge of semiotic differentiation so resolutely, although each in her or his own way. The paradox animating Woolf's art is that the transcendent moments of being she pursues can only be achieved by manipulating transience and discontinuity, just as Lily Briscoe can only bring unity to her painting in To the Lighthouse by dividing it into parts with a stroke across the center. In The Waves, for example, Bernard resents that the fictions he makes necessarily distance him from what he seeks to open up through them. But, paradoxically, he cannot achieve a saving oneness with what lies beyond him without employing 
the very differentiating capacities of language which testify to his separateness.

Lawrence's notion of union is more passionate and physical than Woolf's, but the most vital moments in his works are similarly those confronting the paradox that he must use multiplicity and differentiation if he wishes to transcend them. When he tries to take too direct a route to Being, he lapses into a polemical rigidity antagonistic to the life force he seeks to embrace and express. Ultimately, and ironically, Lawrence transcends the ephemeral, artificial realm of signs by developing a style. By manipulating signifiers through the pulsating rhythms of language and the symbolic suggestiveness of colors, natural objects, and primitive rituals, he evokes indirectly the primal "blood-knowledge" no words can immediately deliver. Although Woolf and Lawrence share a desire for transcendence, their very quests for oneness give evidence of the ubiquity of differences.

In order to clarify further how James, Conrad, and Ford participate in the novel's turn away from realism, let us revisit one last time the four dimensions of fiction which have been central to our textual analyses: the aspects that display the work's world, the power and authority of the narrator, the temporal unfolding of the work, and the relation between the reader's consciousness and the modes of subjectivity encountered in the work. In each of these four areas, as I have tried to show, the literary impressionists transform the existing generic norms by taking their implications to an extreme that finally subverts them. As I have argued, James, Conrad, and Ford radicalize the conventions of realism in ways that lead beyond it to the rejection of representation as the central mission of the novel. The development of the modern novel is thus an interesting case where innovation within the norm results in an overturning of the norm, where the pursuit of the prevailing possibilities and tendencies within a genre ultimately transforms its conventions into the opposite of what they were.

This process is perhaps most clearly evident with the first of our four dimensions, the construction of aspects. Where conventional realism achieves verisimilitude through the harmonious mutual completion of partial, incomplete perspectives, the literary impressionists call attention to consistency building either by interrupting it or by thematizing it. Subsequent modern fiction extends and radicalizes these strategies of fragmentation and thematization in order to foreground the unreflective synthesis of aspects on which realism depends. Joyce combines both strategies, for example, in Ulysses. In an almost Jamesian manner, each of the novel's 
many different styles is a thematized process of composing the world which is generated and controlled by certain assumptions and procedures. The novel's proliferation of modes of vision calls attention to our dependence on hermeneutic constructs. It demonstrates as well their potentially boundless multiplicity and questions whether they can ever be harmoniously reconciled.

Thematization therefore results in fragmentation. The division of Ulysses into an incompletely consistent series of competing ways of understanding is less a representation of the world than an extended epistemological commentary on how the world is constituted. Similar to Conrad's and Ford's fragmented narratives, Ulysses refuses to harmonize in a way that calls into question the assumption that reality must be determinately "there" because it fully coheres. Like Marlow's disconnected series of perspectives in Lord Jim or Dowell's rambling reflections on his past, Joyce's novel may be more "realistic" than fictions that satisfy our desire for coherence, but it is also paradoxically often less lifelike precisely because our efforts to compose our everyday worlds into comprehensible patterns are ordinarily not challenged so strenuously. Hence the contradictory praise Ulysses has received as a triumph of naturalism and as a mammoth technical tour de force.

The narrator is the foundation of a novel's world, and here too the literary impressionists challenge the conventions of representation with the aim of enhancing realism but with the result of subverting it. Whether third-person or first-person, omniscient or limited in knowledge, the narrator in traditionally realistic works typically guarantees the authenticity and veracity of the story. This seems unrealistic to James, Conrad, and Ford, however, and they experiment with various modes of narration which insist on their verisimilitude to the actual hazards and fortunes of interpretation. Subsequent twentieth-century fiction of ten similarly examines self-consciously the epistemological implications of narrative authority instead of quietly exploiting it for realistic effect. In the modern novel, authority is typically either suspended, or asserted only by undercutting itself ironically, or exhibited not as a mastery of the real and the true but as a capacity to invent, manipulate, and reflect about meaning.

For example, although sometimes granted a transcendent perspective, Woolf's narrator frequently suspends her authority so that her voice and her presence mingle indistinguishably with the consciousnesses of the novel's characters. Not intrinsically above them, she too participates in their quest to overcome differences. Mann and Kafka allow themselves 
omniscient narrators only by undercutting our customary certainties with such ironic force that the reader's expectation of authoritative orientation is simultaneously fulfilled and thwarted. Proust's first-person spokesman Marcel and Borges's third-person narrative presence are authoritative precisely because they enjoy such hermeneutic resourcefulness and semiotic dexterity that their endless play with their own capacity to create meaning calls into question the stability and determinacy of the world. In all of these ways, the function of narration in modern fiction is less to guarantee the authenticity of the tale than to make the reader reflect about meaning and interpretation through the challenges of the telling.

In the transformation from realism to modernity, the role of time in the novel also changes so that it is no longer primarily the medium of representation. Time emerges instead as a topic of dramatic interest in its own right because it is the basis of meaning. The time of traditional realism is typically the progressive, teleological unfolding of aspects which reveals the state of affairs they hold. Interruptions and reversals may defy the reader's expectations, but they are surprising for the very reason that we anticipate a consistent, unbroken continuation of the aspects that have so far displayed the work's world. Because our everyday experience of the world is inherently temporal, the transitive activity of unfolding aspects can itself be an aid to verisimilitude by creating the illusion of lifelike happening.

Time itself is dramatized in modern fiction as the medium that not only makes possible but also simultaneously limits our powers to mean and understand. Proust and Faulkner exemplify these poles. For Proust the discovery that we are entrapped in time is liberating. Not only is the past an infinite resource for imaginative reflection. The temporal horizons of any given moment can also be traversed by consciousness in an endless variety of ways to establish ever-unpredictable connections with other moments. Where James's depiction of the present of reflection reduplicating the past of perception celebrates temporal distance as the enabling condition of self-consciousness, Proust portrays the fissure between the present of imaginative creativity and the past of experience as the basis of our boundless freedom to reinterpret and even reinvent the meanings of our lives.

By contrast, Faulkner shares Conrad's sense that time's passage is not redeeming but damning because it demonstrates the limits of our powers. For both of these writers the creation of meaning can only explore the bonds of time but cannot transcend or transform them. Where Conrad's tales of memory dramatize the paradox that the past is both stable because 


\section{Epilogue}

permanently fixed and ephemeral because no longer fully recoverable, Faulkner emphasizes the constricting substantiality of the past. In Faulkner's world the burden of the past weighs more heavily on consciousness with every passing moment as its mass accumulates and as the sheer relentless motion of time's passage presses ever onward, oblivious to human wishes and needs. Although they interpret it so differently, time itself is the major player in the dramas of Proust and Faulkner because its characteristics are a decisive determinant of our power to signify.

The relation between the subjectivities of reader and work undergoes an analogous transformation. Traditionally the enabling condition of representation, intersubjectivity emerges as a major dilemma for modern fiction as the pact between reader and work comes into crisis. David Lodge is one of many critics who have noted that the realistic tradition "depends upon . . . the assumption that there is a common phenomenal world . . . located where the private worlds that each individual creates and inhabits partially overlap."4 Mimesis may demonstrate and solidify intersubjectivity through the mutual disclosure and reciprocal confirmation of the reader's world and the world of the work. Or it may exploit the differences between their two spheres in order to extend the reader's horizons-building on the shared ground of the familiar to assimilate the unfamiliar.

The assumption that a free and full exchange between subjectivities is readily possible seems unrealistic to the literary impressionists, however, and they challenge representation to attune itself more closely to the hermeneutic problems posed by the otherness of other minds. This challenge is carried further by novelists after them. Relentlessly reducing meaning down to its ultimate constituents, for example, Beckett's voice seems paradoxically ever more remote and yet ever more intimate as it approaches perilously close to the absurdity of a private language. Our strained efforts to hear it despite its increasing isolation heighten our participation in its bizarre extremity; at the same time, however, we become aware of how tenuous and arbitrary the conventions are which unify us as a community of speakers. Woolf celebrates communion as much as Beckett tempts solipsism. But her moments of oneness always carry with them the recognition that the discontinuity between selves is as much a precondition of any merger of worlds as it is the reason why misunderstanding generally prevails. "Here was one room; there another," thinks Clarissa Dalloway, "that's the miracle, that's the mystery."

${ }^{4}$ David Lodge, The Modes of Modern Writing (London: Edward Arnold, I977), p. 40.

${ }^{5}$ Virginia Woolf, Mrs. Dalloway (I925; rpt. New York: Harcourt, Brace and World, I953), p. I93. 
If the endless variety of modes of construal makes possible a multiplicity of different, incompatible worlds, then modern fiction asks whether this semantic creativity might itself produce new barriers to the exchange of meaning. Semantic multiplicity may expand our powers of expression, but it may also generate windowless monads incapable of understanding and communication. Hence the preoccupation of many twentieth-century novelists with extreme psychological states or their construction of strange, fantastic realms that insist on their irreducible otherness. Once again intersubjectivity emerges as a problem for epistemological reflection instead of tacitly supporting the illusion of reality.

Not all readers have been pleased, of course, by the modern novel's challenges to the conventions of realism. ${ }^{6}$ Complaints about the failure of a novel to tell a story or represent a world risk blinding the critic, however, to the purpose served by defying his or her expectations. This may be, as I have argued, to encourage a deeper, more self-conscious understanding of what it means to narrate, interpret, or represent. If one regards representation and storytelling as valuable activities, then fictions that explore the hermeneutic and semiotic foundations of reality and narration deserve to be considered important as well-but important in a different way, just as reflection differs from the unreflected or critical detachment from vicarious involvement. To reflect about how worlds are constructed is as worthy an enterprise as building them and participating in them imaginatively.

One danger, however, of modern fiction's emphasis on hermeneutic reflection rather than participatory immediacy is that its experiments might seem like lifeless preoccupations with technique. Hence Richard Poirier's complaint that too often "the techniques [of modern literature] have no emanation from a discoverable human agency" and even "seem to blanket, to smother the human presences which they might be expected to serve." Poirier is justified in preferring literature in which experimentation is not an end in itself but is subordinate to a "performing self" that innovates in order to test, explore, and expand its capacity to mean. The question of the human purposes of formal innovation must be asked, however, with regard not only to the author, as Poirier does, but also (and perhaps even more) to the reader. Is the performance a vain self-display of privileged powers, or does it acknowledge and enhance our own ability to perform through our participation in its explorations of how meaning is made? In

${ }^{6}$ The classic example is, of course, Georg Lukács, Realism in Our Time, trans. John and Necke Mander (New York: Harper and Row, 197I).

${ }^{7}$ Richard Poirier, The Performing Self(London: Chatto and Windus, I97I), p. 8. 


\section{Epilogue}

the former case the work exploits readers by invoking our powers of constitution for its own ends, and we as readers may feel that what we are asked to give is out of proportion to what we receive in return. In the latter case the work offers readers the pleasure and the challenge of reciprocal self-expansion-the work taking on ever new dimensions too as our new discoveries make us ever more able to meet its requirements. ${ }^{8}$

Because of their transitional role, James, Conrad, and Ford face in two directions in the history of the novel. They point the reader back to the genre's past even as they open up its future. By laying bare the epistemology of representation, their narrative experiments equip the reader to develop a new appreciation of the realistic tradition. Af ter being shown how fiction represents a world by drawing on everyday perceptual processes, the reader of literary impressionism is in a position to reinterpret realistic fiction by making explicit its hermeneutic implications. Because of their innovative self-consciousness about meaning and interpretation, however, James, Conrad, and Ford also offer readers an early view of the modern novel's explorations of the joys and dangers of inhabiting a variable, changing world where sign leads only to sign. Readers of literary impressionism may still at times find modern fiction bewildering. But their experiences with James, Conrad, and Ford may also have prepared them to benefit from its demands. They may have learned to suspend their everyday assumptions about reality in order to reflect about understanding and representation.

${ }^{8}$ Different readers will of course apply this test in different ways. What one reader finds invigorating may leave another cold. This variability is not unique to reader-based judgments, however; it also characterizes all tests for literary value. No matter what criteria they invoke or how "objective" and impartial they claim to be, all critics, in their evaluations, reflect their own presuppositions and interests. The merit of reader-oriented tests for value is that they make this explicit and allow us to see clearly the effect an interpreter's predispositions and aims have on his or her judgments. A reader-based test allows opposing assumptions to compete on an equal basis instead of foreclosing judgment in advance by building one set of presuppositions into the operative standards. 